\title{
Listening Comprehension: The impact of Subtitles typographical features on Game Visual Novel.
}

\author{
Eny Kusumawati \\ Politeknik Elektronika Negeri Surabaya \\ Departemen Teknik Mekanika dan Energi \\ Program Studi Teknik Mekatronika
}

\begin{abstract}
The purpose of this study was to test the impact of typographical features of subtitles including size, colour and position on L2 English viewers' retention and recall of texts in game visual novel, and also the voice effect of the visual game. Quasi experimental research played in this study with 54 students of two departments, with the same characteristics. It was played the game visual novel into both classes, and administered 45 multiple choice test and questioners in the end of the classes. Both classes went through the same procedures, but one class watched the customized subtitled of the visual game novel. The data gathered were subjected to the statistical procedure of paired sample t-test. And, the result showed that the experimental class showed the better result on their understanding of the story, but there is contrarily on their listening comprehension result, that is their vocabulary comprehension, it is found that the both subtitles did not have an effect on participants' comprehension. This study has implications for English language teachers and material developers to benefit customized bimodal subtitles as a mnemonic tool for better comprehension, retention and recall of aural content in game visual novel via Computer Assisted Language Teaching approach.
\end{abstract}

Keywords: Typographical features, game visual novel, subtitles, retention and recall, Listening, vocabulary comprehension.

\section{Introduction}

The rapid development of technology today has brought about real changes and shifts in the world of English education, especially in the area English for Specific Purpose. This condition cannot be separated from today's IT development, that gave birth to many creative things to support teaching methods. One of the impacts is on the teaching supporting materials, especially for listening. With increasingly adequate technological developments, scientists are competing to enrich their teaching materials, especially by developing listening material, visual novel. It is featuring mostly static graphics, most often using anime_style art or occasionally liveaction stills (and sometime video footage). As the name might suggest, they resemble mixed-media novels. This is as another way to enrich the teachers teaching materials are by using visual novel, a medium using the narrative style of literature. They tend to put more emphasis on the plot and on characterization, rather than on action scenes. Visual novels are effectively seen as a digital evolution books, with music, pictures, and occasionally even voice acting or movies. The only major difference between a videogame and a typical visual novel is player interaction. Visual Novels mostly do not have a game play nor interaction outside of continuing the dialogue with a button press or making a decision when a choice pops up, even though the typical game drive the user do a lot more than that. However, those two things also share a lot of things; music, sound effects, animation and voice acting are commonly found in both. Some visual novels even include 'actual' gameplay elements, such as Zero Escape with its escape the room puzzles. Visual novels are commonly made with game engines, such as Unity or Ren'Py (which is basically Pygame with extra code).

This study focusing on the impact of teaching methods using visual game novel on students' 
listening comprehension to enrich research which aims to improve listening from boredom. Another purpose is to attract students' interest to enrich their skills in listening through their own field (ESP). Listening involves three cognitive processing phases-perceptions, parsing, and utilization (Anderson, 1983; 1995). The limited capacity of short term memory among L2 learners makes them tend to forget what was heard while rushing to process the new input (Goh, 2000). Relate them to the development of teaching modality to strengthen L2 retention and recall of vocabulary, there are a lot of sources that become the media for teaching listening, especially in attracting interest of ESP students in Listening session. Kusumawati, E \& Hasan (2018) said that many students believe that movies can develop their listening. Moreover, it showed that movie is the other way to connect the students with the story they like to enhance their listening skill. Full video captioning gave benefit to enhance listening comprehension (Bensalem, A.E; 2016).

Most scholars believe and have been proved that listening comprehension can be enhanced with the addition of images (Guichon \& McLornan, 2008; Stempleski, 2003; Markham, Peter \& McCarthy, 2001) Thus, beside that movies are motivating media due to encompassing various topics and that they are presented with both audio and visual stimuli (Stempleski, 2003), then the benefit of using it for language learning are their images and sound that help set the scene of events and its additional information, like their paralinguistic features, provided as a part of support to listening comprehension (Guichon \& McLornan, 2008).

Other scholars added the theory that the typographical features for scenes play an important role to attract the user (the learner) attention curiosity about the story given on the visual novel Weinman (2010). Immersing in the authentic and vivid English context, through the subtitles and lively conversation, students can see the image and hear the pronunciation, use their background knowledge and thus, fetch the main ideas (Safranj, 2015). Typographical features such as size, colors and positions are paid much intentions, conveying the meaning, and even prioritizing the words in the text to be seen, read and consolidating in mind. The significance of typographical features of subtitles, transcribed lyrics, in a music video to prove the value of typo graphics and the effects they could bring about on viewers' mind to read and understand the lyrics in the least possible time and recalling later (Ashtiani, 2017).

Related to this study, the explicit instruction is used to present the material., well known as direct instruction. There are some steps to support, by setting a purpose of learning, telling the students what to do, the showing them how to do it, and finally guiding their hands-on application of the new learning. Luke (2014) describes that explicit instruction refers to teacher-centered instruction that is focused on clear behavioral and cognitive goal and out-comes. This, in turn is made 'explicit or transparent to learners'. Bernstein in Luke (2014) defines that explicit vocabulary instruction as if featuring strong classification and strong framing, clearly defined boundary knowledge and skill, and teacher-directed interaction. Smith (2009) added that techniques such as webbing that involve students' own perspective in creating interaction that gradually clarify targeted vocabulary may be a way to combine direct teaching and incidental learning in one exercise. In the class when the teacher is presenting he or she can use students' personal experiences to develop vocabulary in the classroom, through informal activities such as semantic association students brainstorm a list of words associated with a familiar word, pooling their knowledge of pertinent vocabulary as they discuss the less familiar words on the list. Semantic mapping goes a step further, grouping the words on the list into categories and arranging them on the visual 'map' so that relationship among the words become clearer. Moreover, in semantic developing materials, words are grouped according to certain features, usually with the aid of chats that graphically depicts similarities and difference among features of different words. Then analogies are a useful way to enhance thoughtful decision about relationships among meanings of words. Some studies support that the explicit vocabulary instruction is more effective than other (Dakun, 2000; Hansen, 2009; Mazban, Kamalian, 2013; Zarei, Sepahian, 2015), and direct vocabulary instruction is useful for students at all ability levels (Cynthia, Johnson: 2009).

Some of the research that has been done has provided clear evidence that many ways are done to be able to improve listening skills to students, including with developing the teaching strategies, enrich the teaching materials, or modify some ways of material, but there is still no research that connects the typographical novel features with increasing students' ability to understand 
vocabulary through their listening skill. This study tries to connect the gap to proof whether there is any correlation between typographical features on visual novel and the students of L2 through their listening as their bimodal. Listening is an interesting topic for further investigation. Especially if it is associated with the use of bimodal material that has developed a lot today. And this is thought to be one way to enlightening the students reading need, and the other reason is to avoid the boredom of the old ways to enjoy the literacy, especially on novel.

\section{Methods}

With quasi experimental, used pre-test and posttest design. Explicit instruction and natural instruction method were used in those experimental classes. The subjects were the $3^{\text {rd }}$ semesters of classes from Computers engineering department and Informatics engineering department of Politeknik Elektronika Negeri Surabaya. They were chosen because those students departments have the same characteristics and level of English proficiency.

Before the experiment conducted, both classes were ensured to be equal in all aspects by observing both classrooms, interviewing the English teacher taught in both classes and examining the English scores in the previous semester. Those were carried out as the efforts to reduce the threats towards internal validity (Ary, Jacob \& Sorensen. 2006: 298). The data of those two groups are shown in the table 1 .

Table 1. The Qualitative Features between two classes.

\begin{tabular}{|l|l|l|l|}
\hline No & Features & $\begin{array}{l}\text { Visual Games Novel } \\
\text { Group- VGN (Group A) }\end{array}$ & $\begin{array}{l}\text { Conventional Visual } \\
\text { Novel Group - CVN } \\
\text { (Group B) }\end{array}$ \\
\hline 1 & Number of students & 27 & 29 \\
\hline 2 & Mean scores for English Subject & 50.07 & 50.55 \\
\hline 3 & The schedule of English subject & Monday 3-4 & Monday 7-8 \\
\hline
\end{tabular}

Taking the qualitative features in those two classes, it concluded that they were not significant regarding students' number in the portion of mean scores for English subject. It can assume that both classes were homogenous. It is to prove that both groups are equal to avoid the bias.

After that, the researcher and teachers were collecting the score of both classes to compare. It used to determine the effect of the treatment into both classes based on their proficiency. Flashback before the treatments started, the researcher and teachers collected the students' data from their previous semester, to ensure that both classes were equal on their language achievement.

When the experimentation began, both classes had 2 different instructions in the class. Group A with Explicit instruction, and group B with natural instruction. They had the same listening session, but with different visual type. One class (group A) used with the English visual game novel, and another class (group B) used the conventional visual game novel. Due to this study, the researcher prepared two types of visual material to present in those classes. But, those materials had the same audio material for listening. After conducting four meetings, the post-test was given. While in the processing of teaching and learning, a teaching schedule alternation between the teacher and the researcher was applied in order to minimize the possible threats. By alternating the teaching schedule between the teacher and the researcher, the atmosphere of teaching and learning was conditioned casual like the usual classes to avoid the students suspicious of under the research study. The discussion on the detailed lesson plan, including teaching strategy, media/ materials, and assessment were carried out to the process of experiment. Those things are used to ensure that the lesson plan and the instructions could be applied appropriately. The details of the lesson plan were given to the teachers before starting the class. The teaching schedule alternation between the teacher and the researcher is shown in the table 2 .

Table 2. The Teaching Schedules

\begin{tabular}{|l|l|l|}
\hline Meeting & Group A - VGN & Group B - CVN \\
\hline 1 & & \\
\hline 2 & The English teacher & The researcher \\
\hline 3 & The researcher & The English teacher \\
\hline 4 & The English teacher & The researcher \\
\hline
\end{tabular}




\begin{tabular}{|l|l|l|}
\hline 5 & The English teacher & The researcher \\
\hline 6 & The researcher & The English teacher \\
\hline
\end{tabular}

Before starting the class, the teacher and the researcher would do some discussions about the plans, the threats, the obstacles, and some imagine condition that would be the barrier in the class. Then tried to find the alter list strategies as the solutions to keep the class working out. Four (4) visual game novels and conventional visual novel were used in the experimental classes.

\section{Procedures}

\section{Data Collections.}

To complete the purpose study, the same topic visual game novel was chosen, and used in listening for both experimental groups. This visual game novel was chosen because it is required on the syllabus. One of the syllabi discussed about Campus life.

After watching the movie, both groups received questionnaires which aim to elicit students' feedback regarding the use of the visual game novel in the class, and also to investigate the relationship between movie viewing and students' performance. Both experimental classes were then given paper based quiz with vocabulary and listening activities in multiple choice and cloze test.

\section{Pre-test}

To investigate the effects of subtitles on listening comprehension, the researcher used SPSS 19. The result obtained from the pre-test of all the groups were presented that the mean score of the group A is 50.0741, and the mean score of group B is 50.5517 .

The result of the statistics showed that all groups are almost the same regarding their vocabulary knowledge, and there is no significant difference between them.

\section{Post-test}

After analysing the pre-test result, at the end of the treatment, the result obtained from the post-test analysed. The descriptive statistics of the participants' performance in those two groups show that the mean score of group A is 51.4815, and the mean score of group B is 38.4828.

The mean score of each group and comparison with the mean obtained from pre-test revealed that both experimental groups have performed better on post-test and the mean of two groups are significantly increased. As shown by group A with the mean score 51.4815, the group with subtitle significantly outperformed higher than the other group. Another experimental group, the visual game novel without subtitle had the lower.

\section{Analysis}

1. There is any influence using visual Game Novel (VGN) and Conventional Visual Game Novel (CVN) on students' listening comprehension?

After the process of treatment, the posttest was given to group A, Visual Game Novel (VGN), and group B, the Conventional Visual Game Novel $(\mathrm{CVN})$ which lasted for 60 minutes for the listening session with questions.

Then the T-test with independent sample testing is used to find out the answer to the research problem whether any difference or no difference between the two groups. Based on the result of the posttest in the VGN group and the CVN group, it was shown that the mean score of the groups were 51.4815 and 38.4828 respective.

Roughly, it can be concluded that the main score of the VGN group, that is group A, the group using Visual Game Novel (VGN) was higher than the group B, the group using Conventional Game Novel (CVN).

\section{The treatment used to apply during the experiment conduct}

Based on the result of posttest of the group A (VGN) and the group $\mathrm{B}(\mathrm{CVN})$ on their comprehension, which is used T-test with independent sample testing to find out the result that the mean scores of the VGN group is 46.6667 and the CVN group is 34.0690 respectively. It can be concluded that the main score of the group using Visual Game Novel was significantly higher than the other group, that is the group using conventional Visual Game Novel.

\section{Those two kind of visual novels and the treatments of the teachers applied has any relation impact.}

Based on the posttest analysis of the group A (VGN) and the group B (CVN), which is used Ttest with independent sample testing to find out 
the answer of the research problem, it was revealed that the mean score for the group using visual game novel is 5.0370 and the group conventional visual game novel is 4.3448 . It is revealed that there is no significantly different. They do not have any difference. It means that the test results from both groups showed no increase in vocabulary comprehension.

\section{Conclusion}

Based on the statistics numbers, there are two experimental groups, the visual game novel in group A (VGN), and the other class as group B used the conventional visual novel (CVN). They were under different instructions, explicit instruction group and natural instruction group, and they also had different treatment media, one group gave the treatment with visual game novel, and the other gave the treatment with conventional visual novel.

Overall, in this study the groups showed enthusiastic response on the media treatment through their listening session. The students get this feeling because they got a new thing on their treatments, the visual game novel series. Many students believe that this media can give some compensation through the audio and visual channel. They can develop their vocabulary comprehension through listening and reading activities. However this statistical data failed to show that they get a greater impact on vocabulary comprehension.

They seemed enjoy the media treatments and the class interactions during the listening session. Some obstacles considered to be the cause of this study, they are; (1) The treatment only played in one session, without repeating. Perhaps presenting more than once would get better result on the students' vocabulary achievement., (2) Some students did not activate their prior knowledge to develop their vocabulary bank during the treatment. This condition is suspected to be the cause of the students failed to enhance their vocabulary comprehension. Because they only understand the novel story through the subtitle and the pictures., (3) The limitation of their vocabulary is the other main cause of the students failed. They cannot explore their limitation through the questions, because of their terminology limitations. Since the written forms of the dialogues and the strips of the visual game novel session played the role, they just received the information from the story without the needs to develop deeper. (4) The explicit instruction method is successfully applied in the class; this treatment has better impact to the students than natural instruction method. Further analyses showed that this treatment has a relationship with the culture, that east culture. Those findings showed that the students' listening does not have any impact on their vocabulary comprehension. Two experiment groups failed to show the development of the students' vocabulary comprehension.

\section{References}

[1] Ary, Donald. Jacobs, Lucy Cheser. Razavieh, Asghar. Sorenses, Christine K. 2006. Introduction to research in Education 8th Edition. Belmont, Wardsworth.

[2] Ashtiani, Farshid Tayari. (2017) The Effect of Typographical Features of Subtitles on Nonnative English Viewers' Retention and Recall of Lyrics in English Music Videos. International Journal of Applied Linguistics \& English Literature. http://dx.doi.org/10.7575/aiac.ijalel.v.6n.7p.12 $\underline{2}$

[3] Anderson, J. R. (1995). Cognitive psychology and its implications ( $4^{\text {th }}$ ed.). New York: Freeman.

[4] Bensalem, A.E. (2016). The Impact of Keyword and Full Video Captioning on Listening Comprehension. Global Journal of Foreign Language Teaching. 6(3), 112-120.

[5] Cynthia, Johnson Drew. 2009. Why Teach Vocabulary?, (http://www.yumpu.com/en/.../whyteachvocabulary-by-cynthia-and-drewjohnson. Accessed July, 1,2015

[6] Dakun, Wang. 2000. Vocabulary Acquisition : Implicit Learning and Explicit Teaching. National Institute of Education. REACT.

[7] Kusumawati, E. \& Hasan. (2018). Implicit Instruction, Subtitles, Vocabulary and Listening Comprehension. Alphabeth, 01 (02), 129-135. Doi: 10.21776/ub.alphabeth.2018. 01.02.06

[8] Guichon, N\& McLornan, S. (2008). The effects of multimodality on L2 learners: Implications for CALL resource design. System, 36, 85-93.

[9] Goh, C. C. M. (2000). A cognitive perspective on language learners' listening comprehension problems. System, 28(1), 55-75. http://dx.doi.org/10.1016/S0346251X(99)00060-3

[10] Hansen, Kristina M. 2009. Vocabulary Instruction, Reading Comprehension, And 
Student Retention: A Review of Literature. Thesis. Submitted In Partial Fulfillment Of The Requirements For The Degree Of Master of Arts in Education. Northern Michigan University.

[11] Markham, P.L., Peter, L. A., \& McCarthy, T.J. (2001). The Effects of Native Language vs. Target LanguageCaptions on Foreign Language Students' DVD Video Comprehension. Foreign Language Annals, 3, 439-445.

[12] Marzban, Amir, and Kamalian, Kimia. 2013. Effects of Implicit Versus Explicit Vocabulary Instruction on Intermediate EFL Learners' Vocabulary Knowledge. ELT Voices-India. Desember 2013. Vol.3

[13] Safranj, Jelisaveta.(2015). Advancing Listening Comprehension Through Movies. Elsevier Ltd.doi: 10.1016/j.sbspro.2015.04.513.

[14] Stempleski, S. (2003). Integrating video into the classroom curriculum. Selected Papers from the twelfth International Symposium on English Teaching. Taipei: Crane.

[15] Weinman, Jerod J. (2010). Typographical Features for Scene Text Recognition. IEEE. IAPR Proc. Intl. Conf. on Pattern Recognition, Istambul, Turkey, August 2010.

[16] Zarei, Abbas Ali. Sepahian, Soheila. 2015. The effects of explicit and implicit instructional techniques (glossing semantic mapping, and imagery) on 12 vocabulary comprehension and production. ACADEMIE ROYALE DES SCIENCES D OUTRE-MER BULLETIN DES SEANCES Vol. 4 No. 3 June 2015 pp. 3040.

\section{Author Profile}

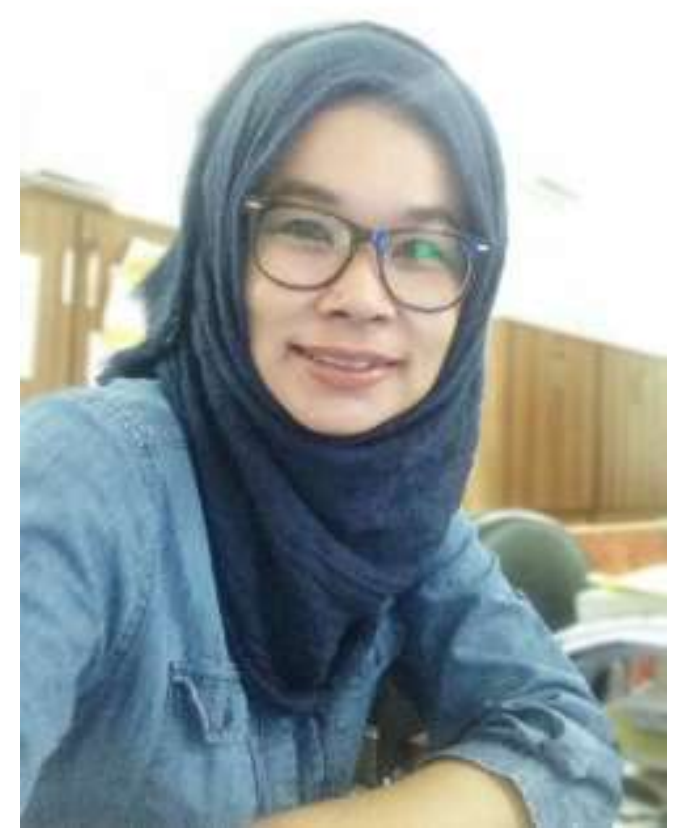

Dr. Eny Kusumawati, S.Pd., M.Pd., is an English lecturer at an Indonesia Polytechnic (Politeknik Elektronika Negeri Surabaya). Received her Bachelor, Master and Doctoral program majoring in Education, Language Assessment, English in ESP and Curriculum Development, respectively. She now, actively doing research and her field area, concerning in ESP to develop and enrich teaching materials, especially in reading. 
Appendixes.

1.

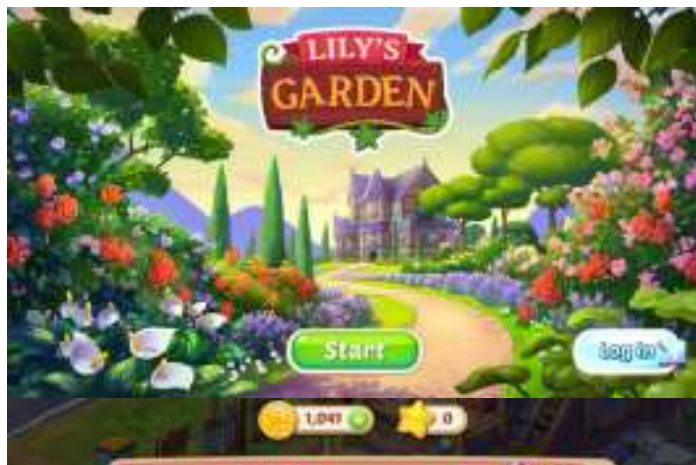

2.

3.

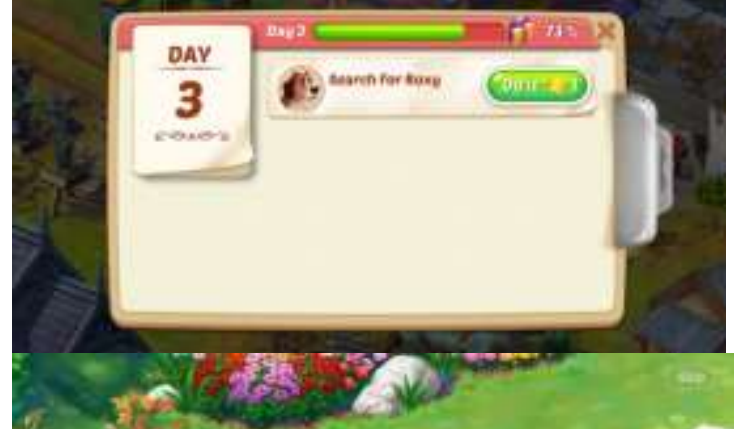

4.
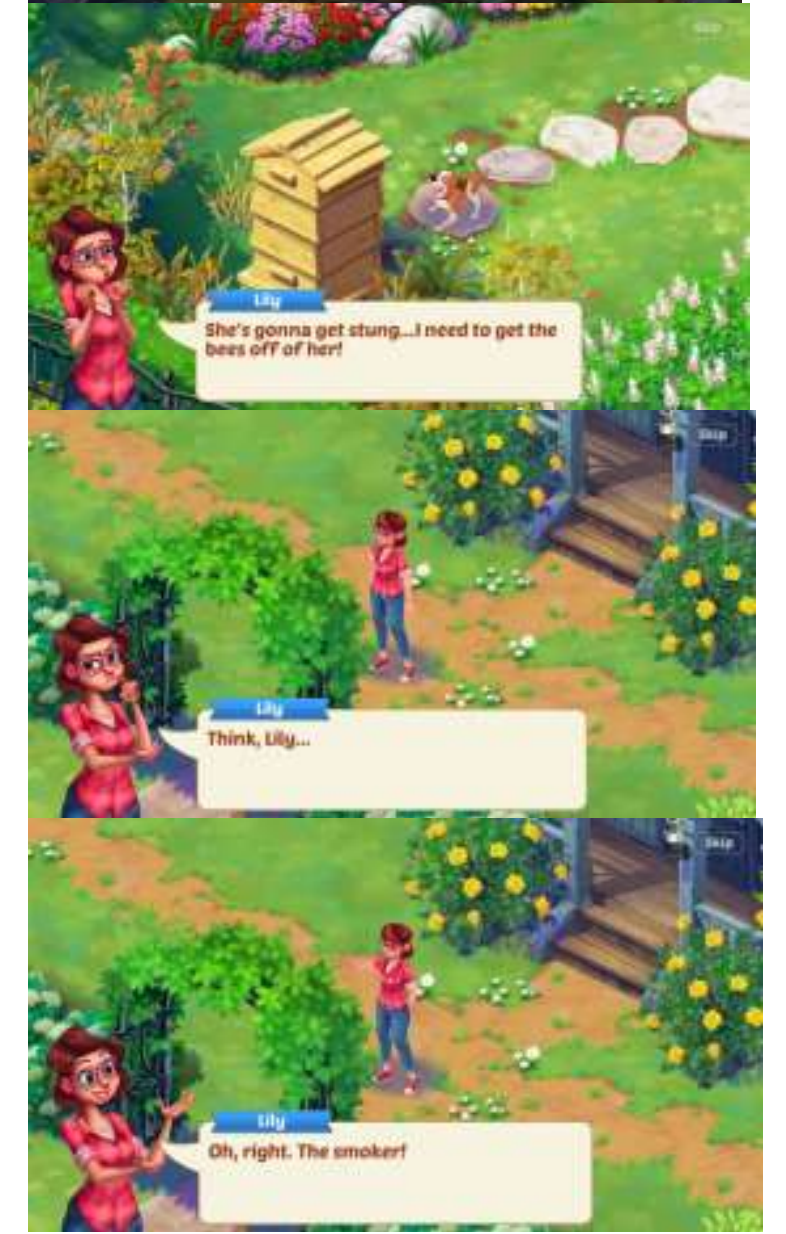
6.

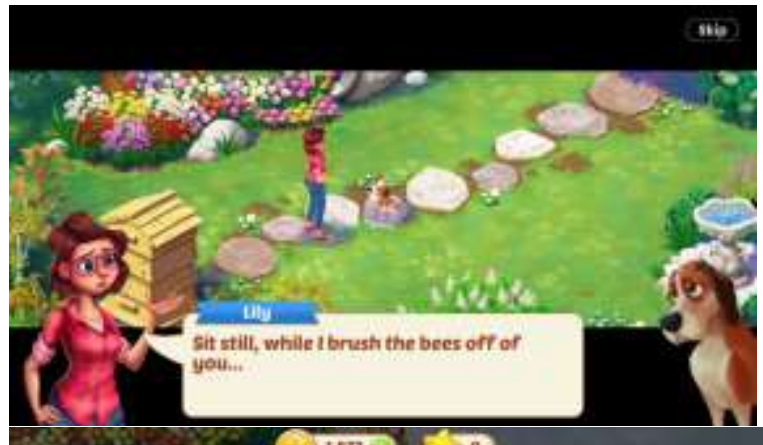

7.

8.

9.
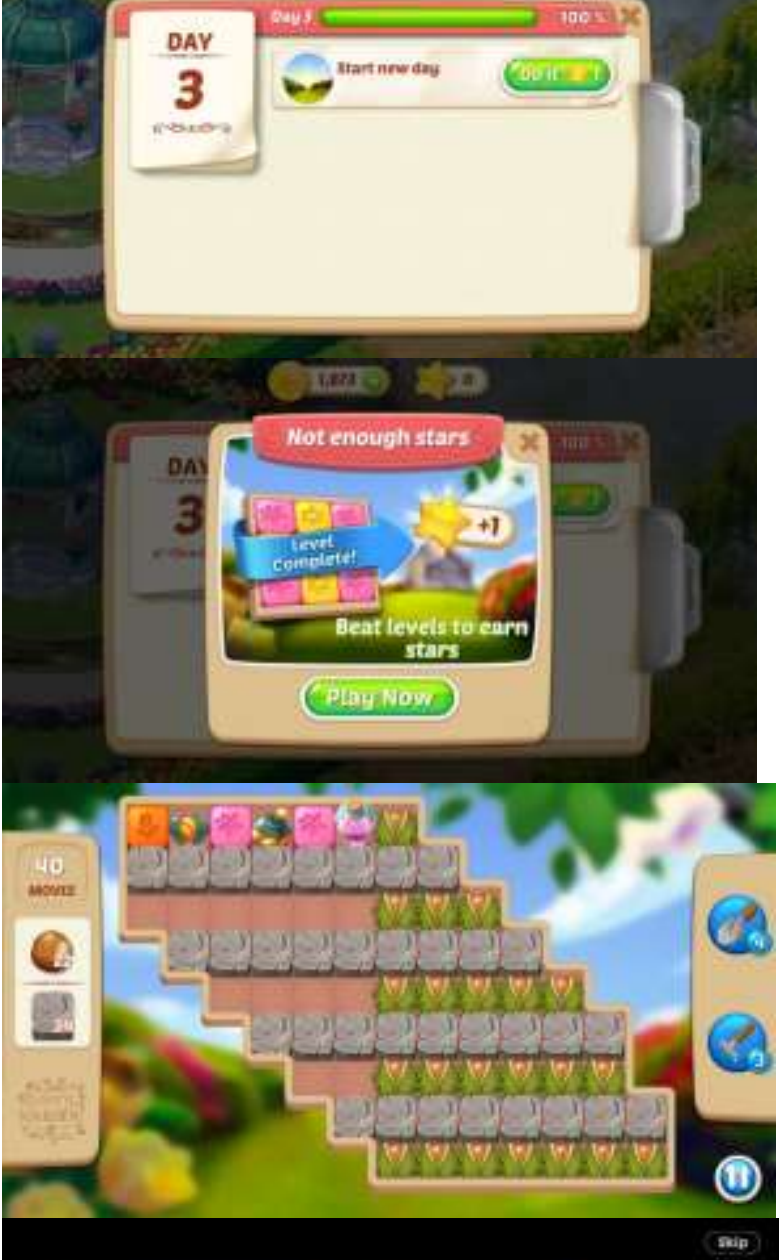

10.

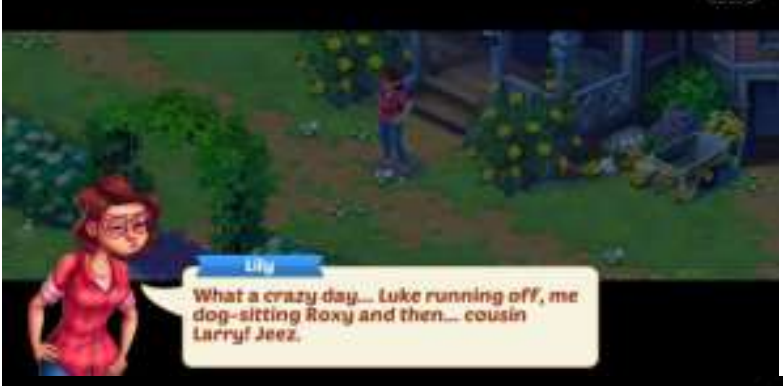

11.

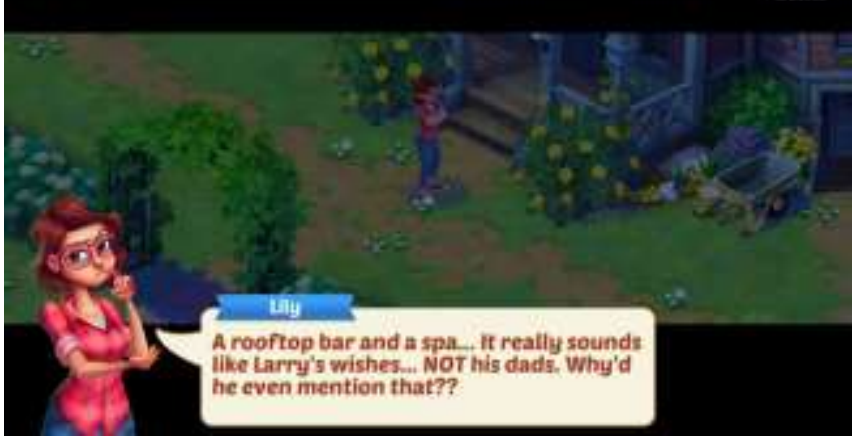


12.

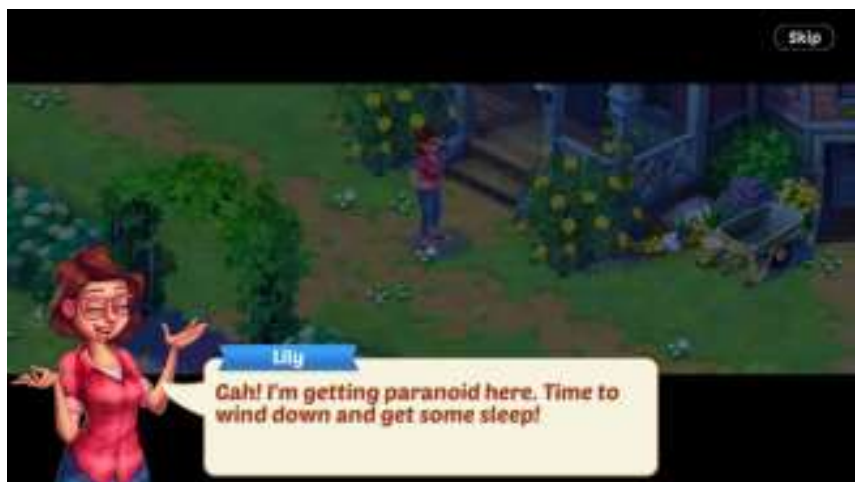

13.

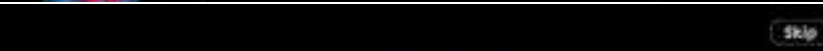

Hey, his car is gone. I sure hope he sobered up before he left...

14. 